\section{Check for updates}

Department of Medicine, Duke University School of Medicine, Durham, North Carolina, USA

2 Department of Medicine, University of Washington, Seattle, Washington, USA

Correspondence to nathan.gray@dm.duke.edu Cite this as: BMJ 2020;369:m2255 http://dx.doi.org/10.1136/bmj.m2255 Published: 11 June 2020

COVID-19

\title{
Covid-19 communication aids
}

\section{Nathan A Gray, ${ }^{1}$ Anthony L Back ${ }^{2}$}

Illness related to the novel coronavirus has driven a global crisis, and many clinicians are facing unexpected and challenging conversations. This guide is a graphic medicine adaptation of text that was created to provide a practical introduction on how to talk about difficult topics related to covid-19. During early spread of the pandemic, the written text and subsequent illustrations were created to promote rapid sharing of communication skills with clinicians across diverse disciplines. The primary text was produced by non-profit organisation VitalTalk, which gives training to support conversations around serious illness.

This guide is not meant to be comprehensive, but it is a starting place for improving conversations with those facing this illness.

The original text is at www.vi-

taltalk.org/guides/covid-19-communication-skills/. 


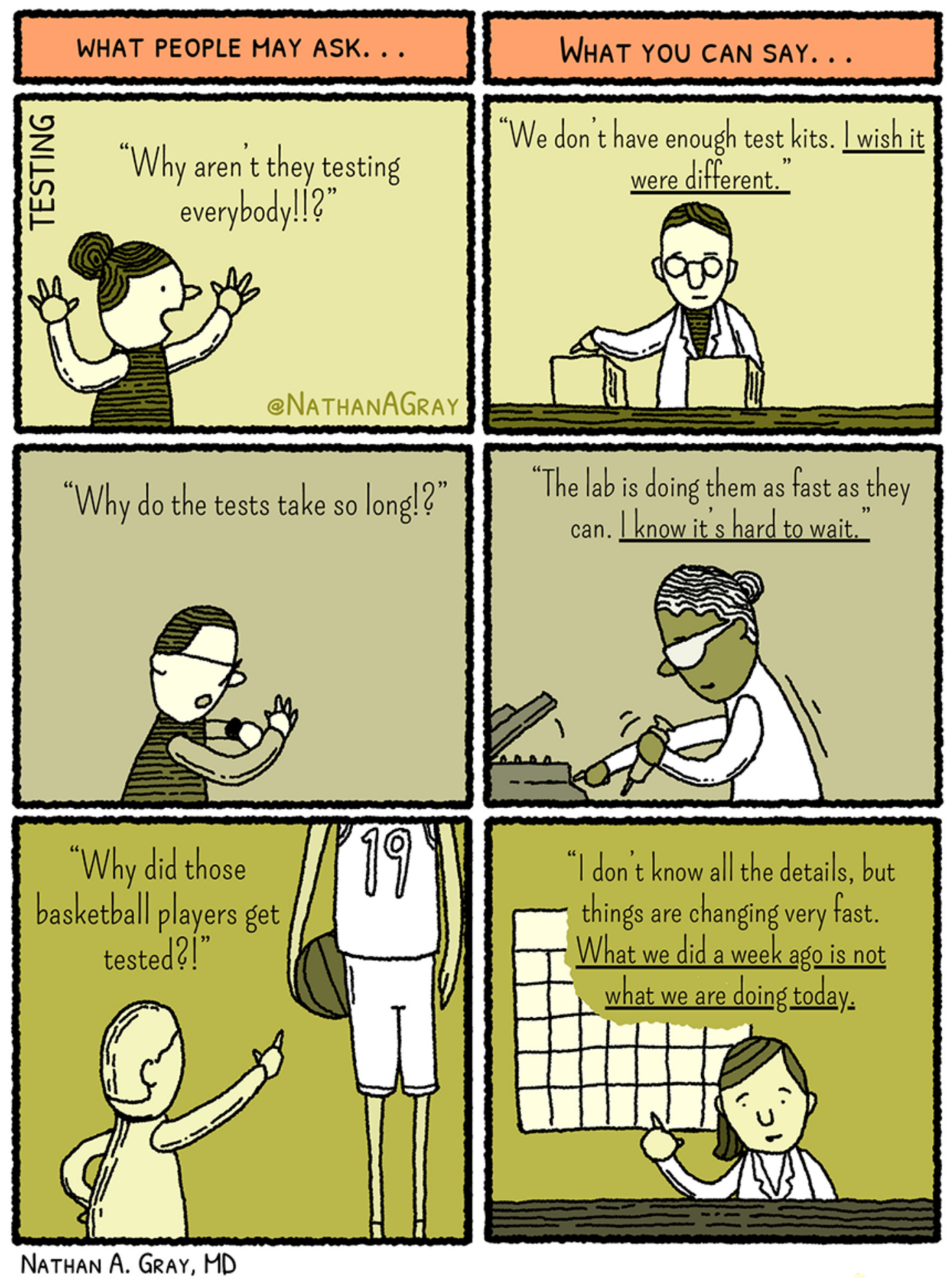




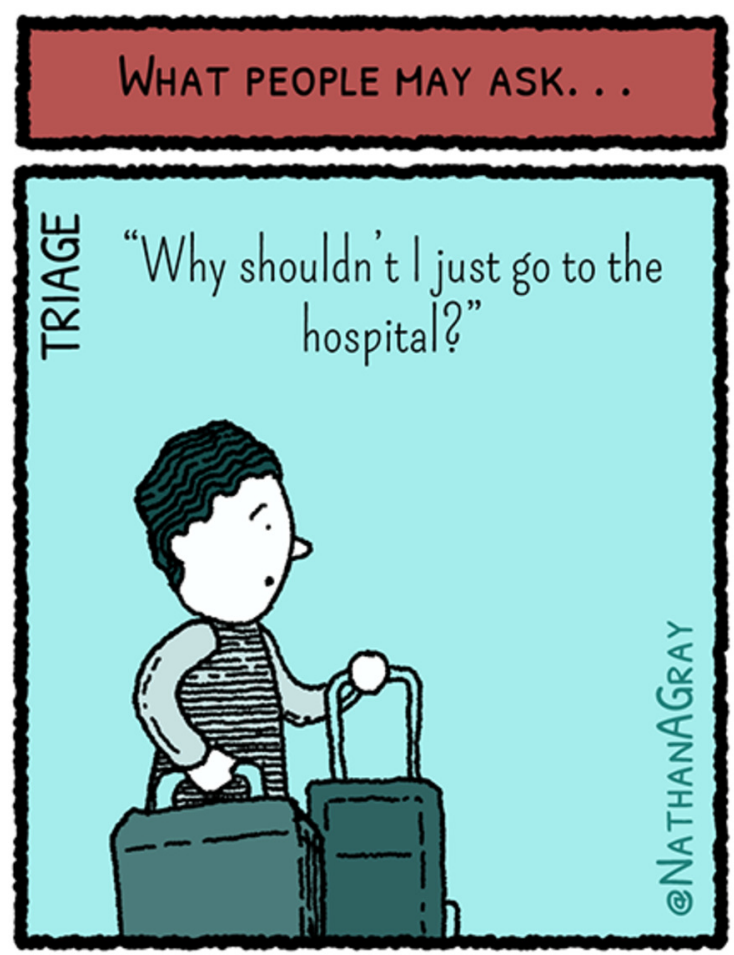

\section{WHAT YOU CAN SAY. . .}

"Our primary concern is your safety. We are trying to organize how people come in. Please fill out the questions online, and you can speed up the process for yourself and everyone else.

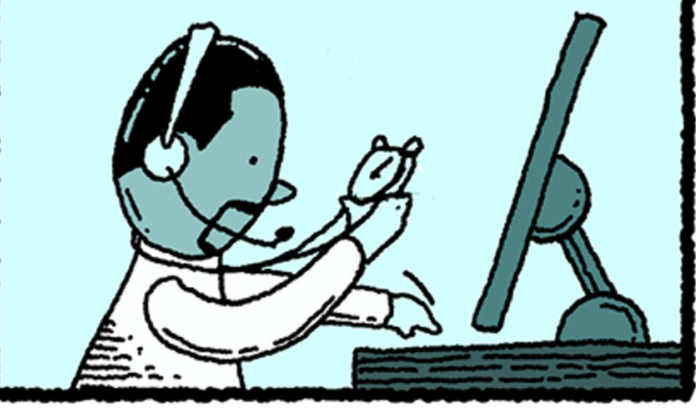

"Why are you trying to keep me out of the hospital?"

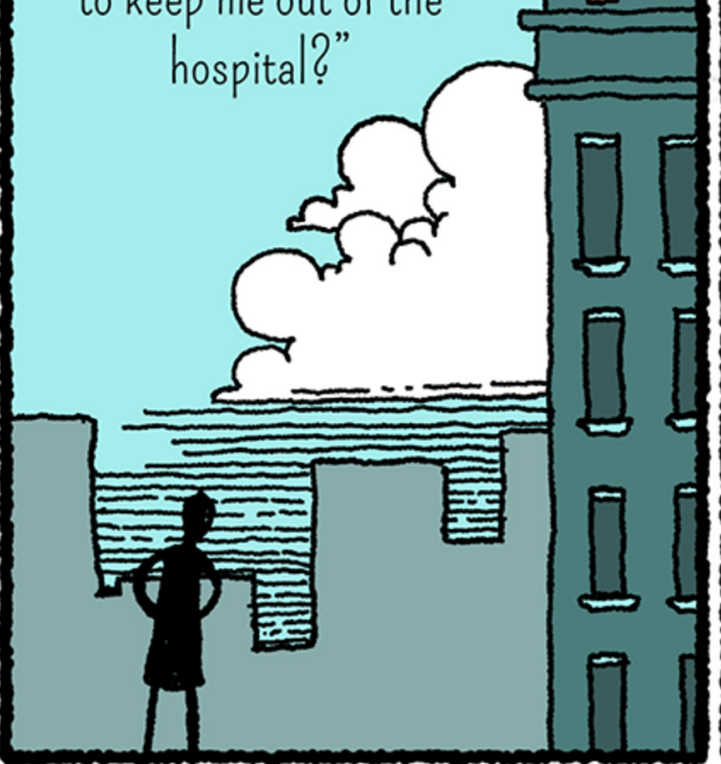

"I imagine you are worried and want the best possible care. Hospital care is important when you need it, but until then we will do our best to meet your medical needs in the community. The safest thing you can do is

Nathan A. Gray, MD WITH text adapted from VitalTalk

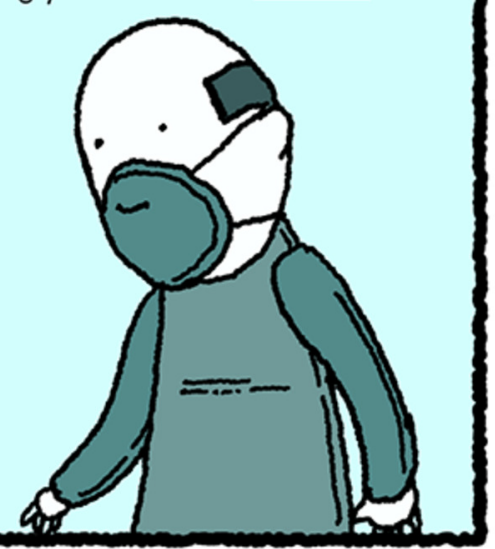




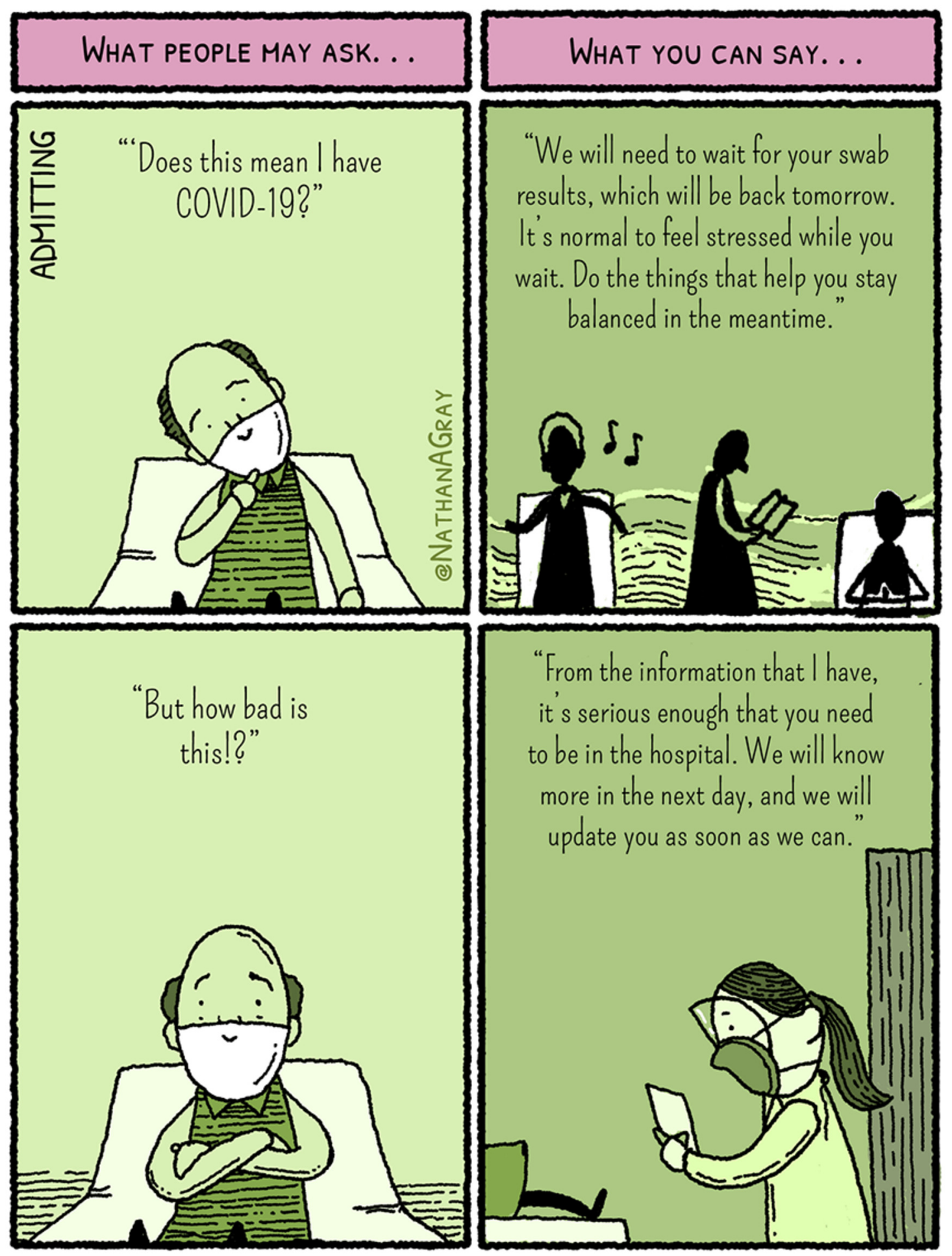




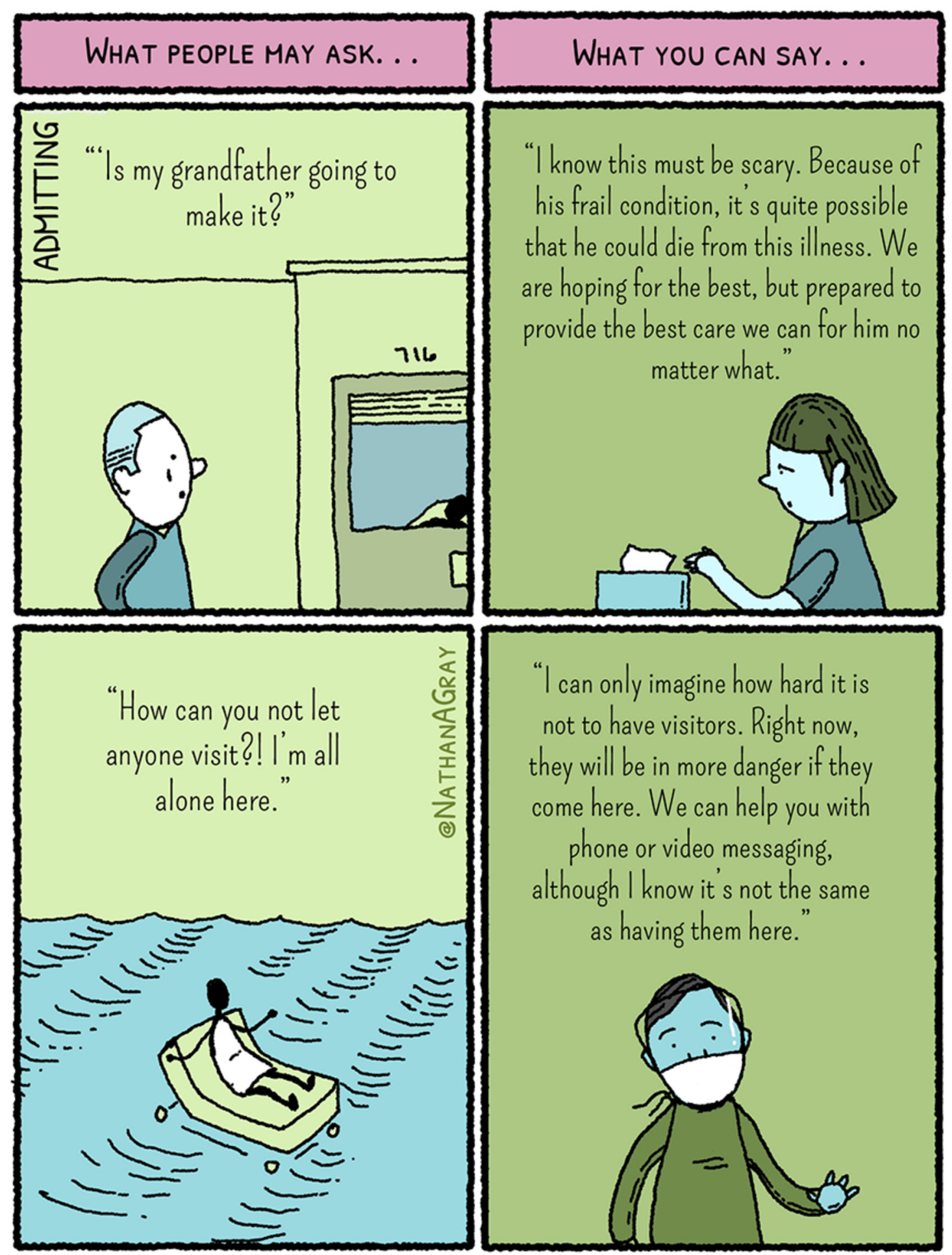




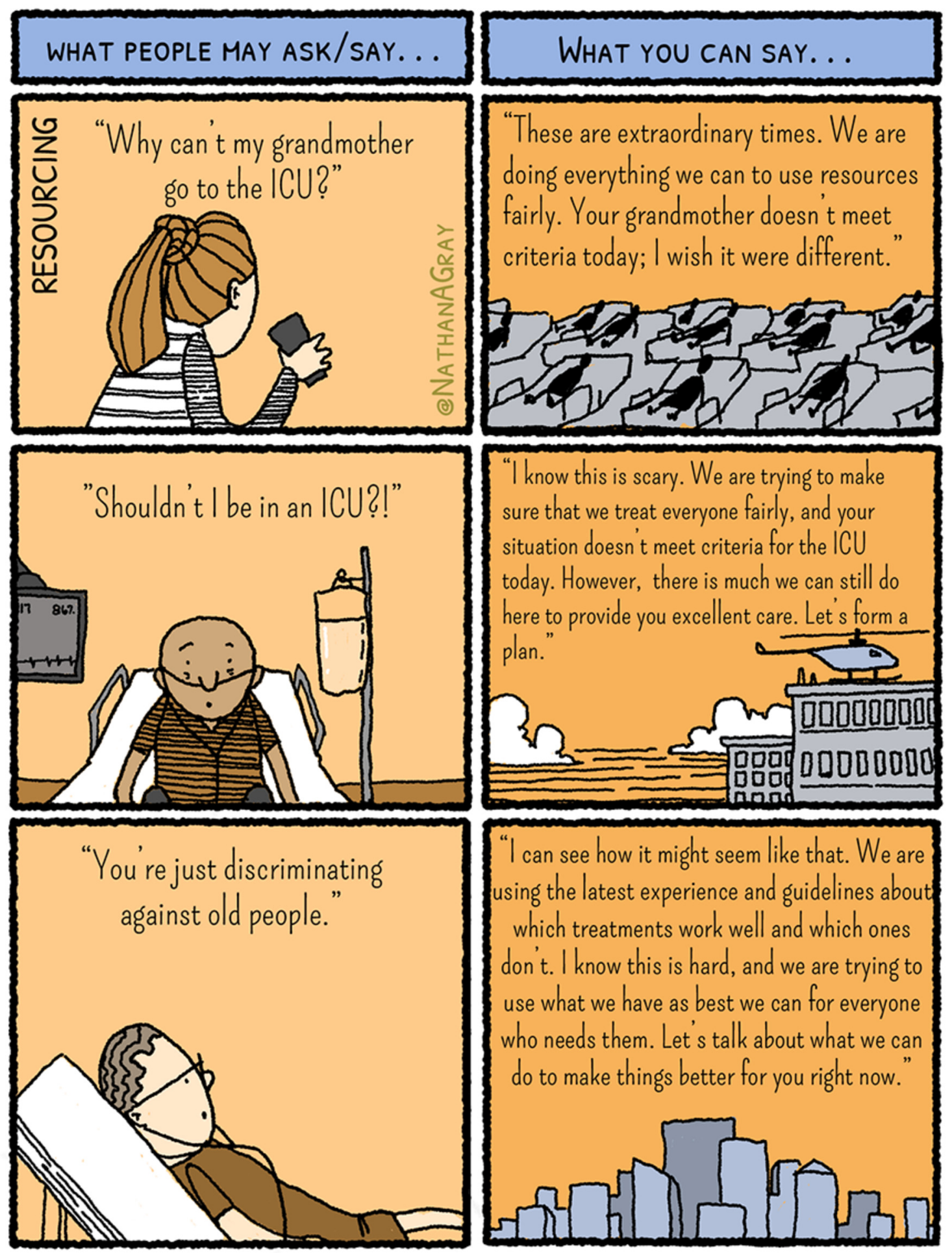




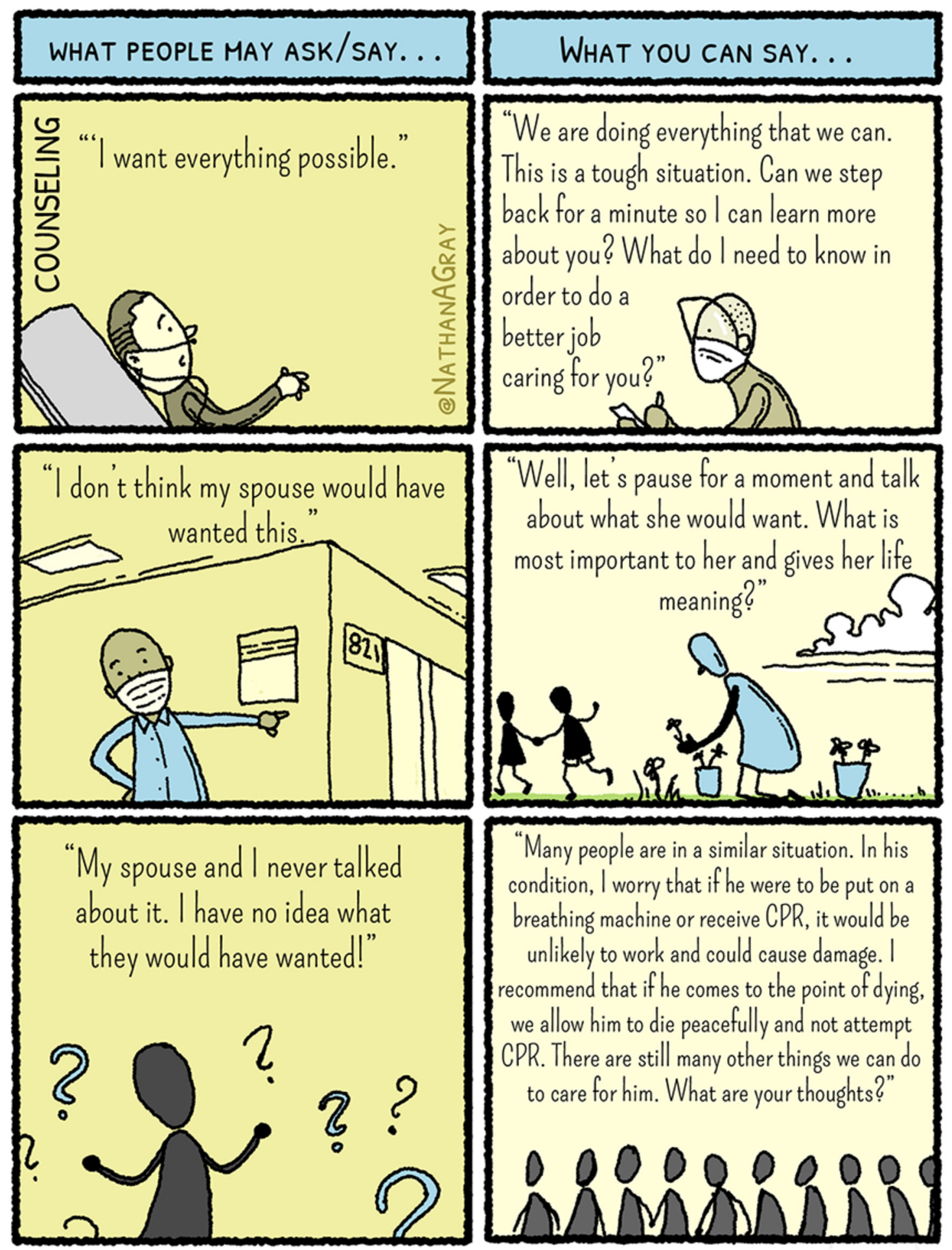




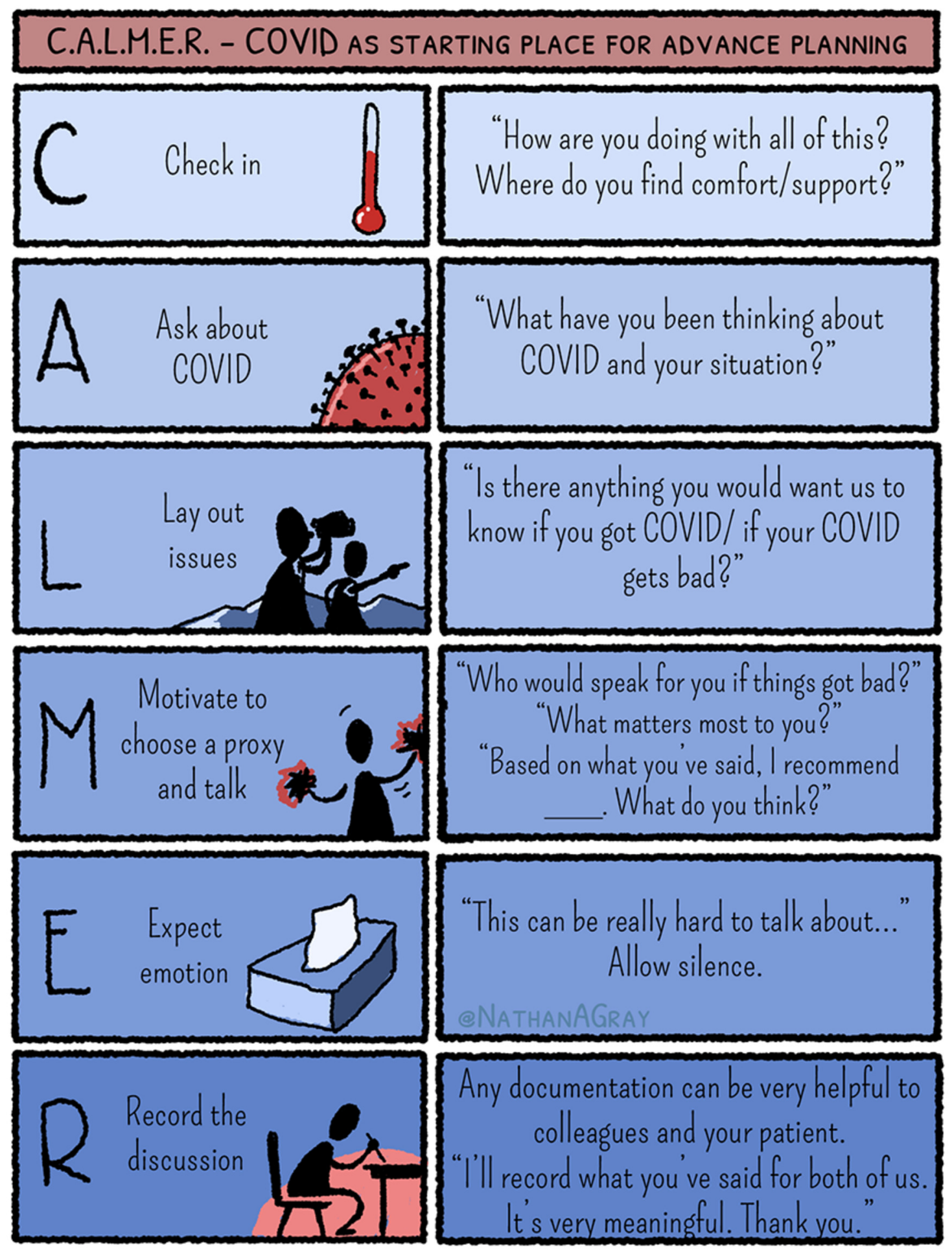



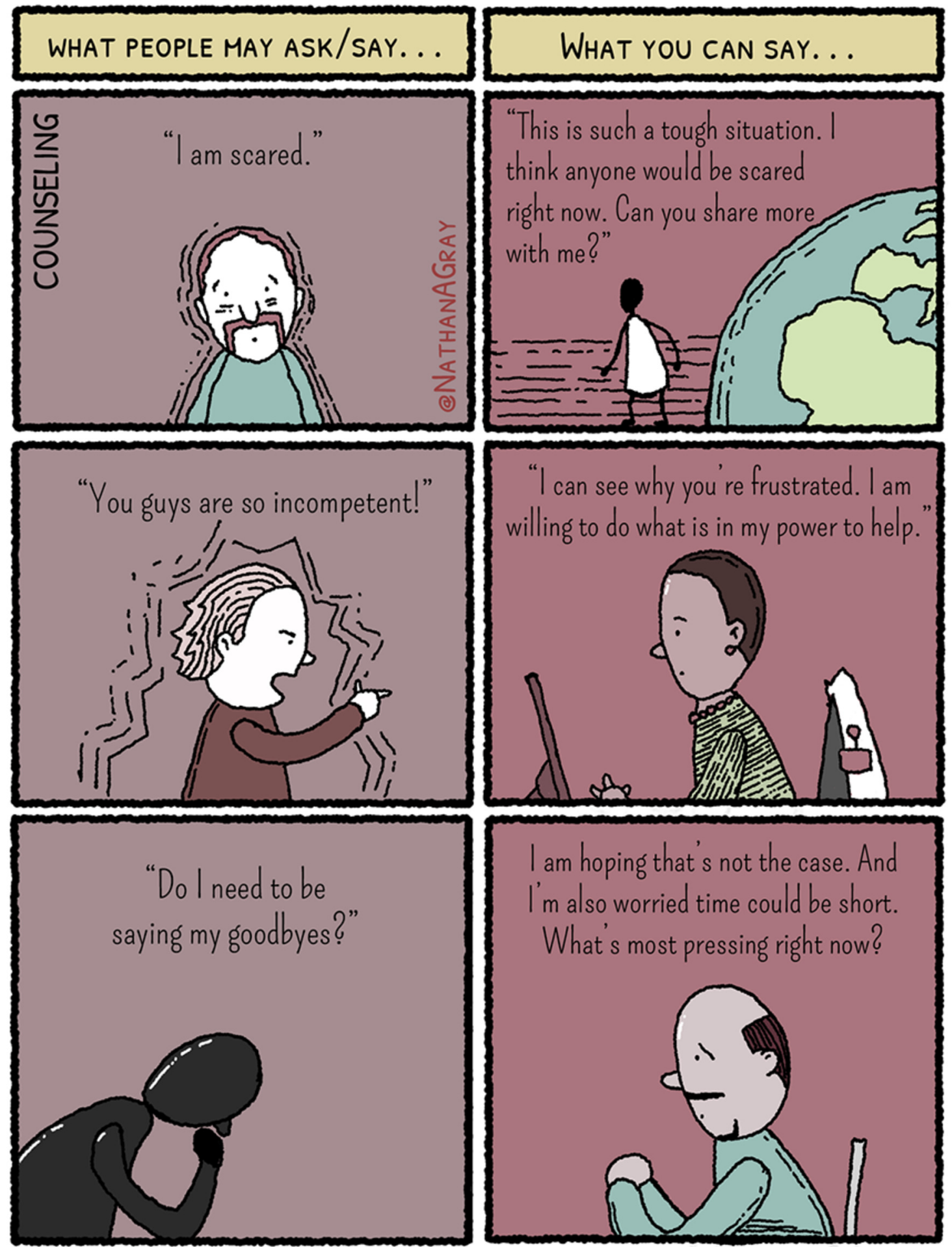


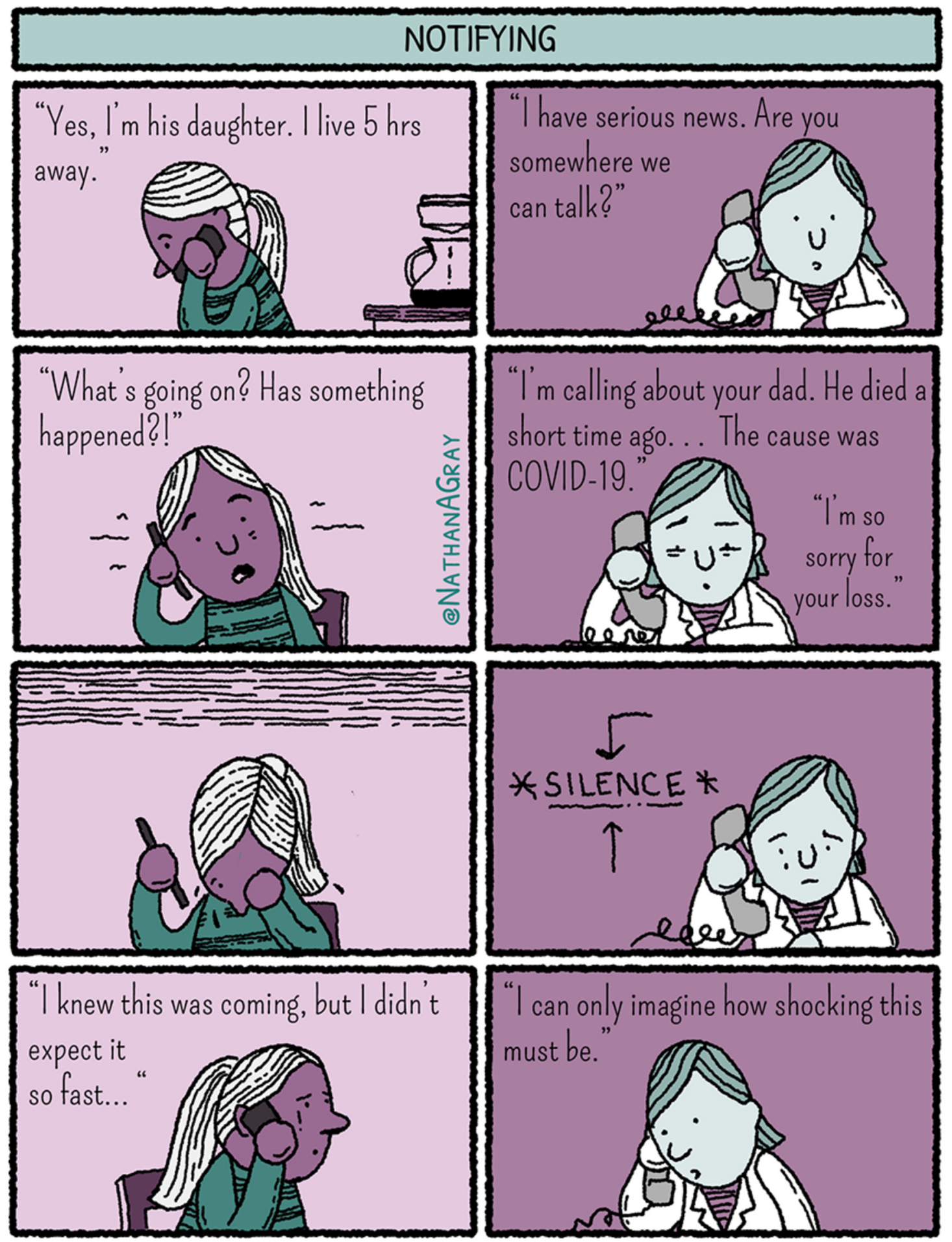




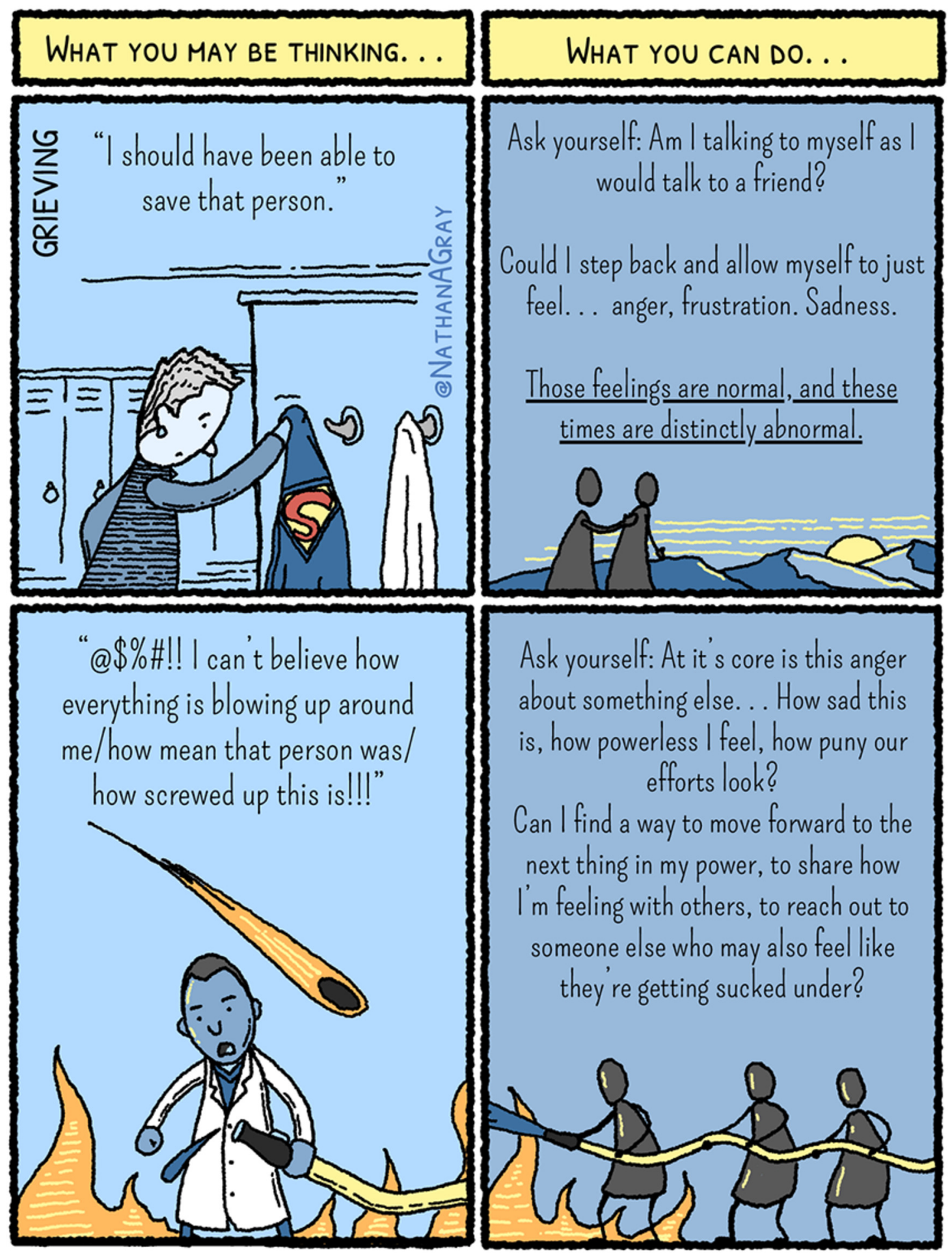

Provenance and peer review: not commissioned; externally peer reviewed.

Patient involvement: No patients were directly involved in the creation of this article.

Competing interests: VitalTalk's covid-19 communication guide was produced in March 2020 and distributed freely online. The initial graphic versions of this work were also adapted in March and distributed freely via social media to disseminate communication strategies to clinicians in a timely manner. VitalTalk is a non-profit organisation. Neither Nathan Gray nor VitalTalk profited financially from creation of this guide.

This article is made freely available for use in accordance with BMJ's website terms and conditions for the duration of the covid-19 pandemic or until otherwise determined by BMJ. You may use, download 
and print the article for any lawful, non-commercial purpose (including text and data mining) provided that all copyright notices and trade marks are retained. 